\title{
Perancangan Turbin Sumbu Horizontal dan Sumbu Vertikal untuk Pembangkit Listrik Tenaga Angin (Studi Kasus di Kota Bengkulu)
}

\author{
Anizar Indriani ${ }^{1}$, Gordon Manurung ${ }^{1}$, Novalio Daratha ${ }^{1}$, Hendra $^{2}$ \\ ${ }^{1}$ Program Studi Teknik Elektro UNIB \\ ${ }^{2}$ Program Studi Teknik Mesin UNIB \\ Email:aniz_raimin@yahoo.co
}

\begin{abstract}
Wind Power Plant is a power plant that uses wind as an energy resources to produce electrical energy. The Bengkulu region which is mostly a coastal area with conditions of strong wind speeds that can be utilized as a source of wind power generation. Wind energy can be utilized as an alternative and renewable energy source using wind turbine. Wind turbine performance depends on the shape, position and dimensions of the turbine, etc. In this study focus on the design of wind power plants with horizontal axis turbine position and vertical axis turbine position. Wind turbine was designed with 3 blades made of wood materials. The permanent magnet DC generator are used for generator in the horizontal axis and vertical axis wind turbine positions with maximum power that can be generated at 800 Watt. Testing of the two types of turbines was carried out on the coast of Bengkulu city. The results shows that the horizontal axis wind power plant design starts rotating at a wind speed of $3.5 \mathrm{~m} / \mathrm{s}$, while the vertical axis wind power plant design starts rotating at a wind speed of $6.5 \mathrm{~m} / \mathrm{s}$. The voltage generated by the horizontal axis wind power plant at a wind speed of $3.5 \mathrm{~m} / \mathrm{s}$ is 12 Volts. The voltage generated by the vertical axis wind power plant at a wind speed of 6.5 $\mathrm{m} / \mathrm{s}$ is 9 Volts.
\end{abstract}

\section{ABSTRAK}

Pembangkit Listrik Tenaga Angin adalah pembangkit listrik yang menggunakan angin sebagai sumber energi untuk menghasilkan energi listrik. Wilayah Bengkulu yang sebagian besar merupakan wilayah pantai dengan kondisi kecepatan angin kencang yang dapat dimanfaatkan sebagai sumber pembangkit tenaga angin. Energi angin dapat dimanfaatkan sebagai sumber energi alternatif dan terbarukan menggunakan turbin angin. Kinerja turbin angin tergantung pada bentuk, posisi dan dimensi turbin, dll. Dalam penelitian ini fokus pada desain pembangkit listrik tenaga angin dengan posisi turbin sumbu horizontal dan posisi turbin sumbu vertikal. Turbin angin dirancang dengan 3 bilah yang terbuat dari bahan kayu. Generator DC magnet permanen digunakan untuk generator di sumbu horizontal dan posisi turbin angin sumbu vertikal dengan daya maksimum yang dapat dihasilkan pada 800 Watt. Pengujian dua jenis turbin dilakukan di pantai kota Bengkulu. Hasilnya menunjukkan bahwa desain pembangkit listrik tenaga angin sumbu horisontal mulai berputar pada kecepatan angin 3,5 m / s, sedangkan desain pembangkit listrik tenaga angin sumbu vertikal mulai berputar pada kecepatan angin 6,5 m / s. Tegangan yang dihasilkan oleh pembangkit listrik tenaga angin sumbu horisontal pada kecepatan angin $3,5 \mathrm{~m} / \mathrm{s}$ adalah 12 Volt. Tegangan yang dihasilkan oleh pembangkit listrik tenaga angin sumbu vertikal pada kecepatan angin $6,5 \mathrm{~m} / \mathrm{s}$ adalah 9 Volt.

KATA KUNCI: Turbin, Vertikal, Horizontal, Tegangan, Pembangkit Listrik Tenaga Angin

\section{PENDAhUluan}

Pembangkit listrik tenaga angin merupakan pembangkit listrik energy terbaharukan yang memanfaatkan angin sebagai sumber energi untuk menghasilkan energi listrik. Wilayah Bengkulu yang sebagian besar merupakan wilayah pantai dengan kondisi kecepatan angin yang cukup tinggi (kencang) dapat dimanfaatkan sebagai sumber pembangkit tenaga angin. Selain energy angina sumber energy terbaharukan lain yang dapat diolah di Propinsi Bengkulu adalah energy surya dan energy gelombang laut [1-8].

Energi angin dimanfaatkan sebagai sumber energi alternatif dan terbarukan menggunakan turbin angin. Kinerja turbin angin tergantung pada bentuk, posisi dan dimensi turbin, arah dan lainnya.

Dalam penelitian ini fokus pada desain pembangkit listrik tenaga angin dengan posisi turbin sumbu horizontal dan posisi turbin sumbu vertikal. Turbin angin dirancang dengan 3 bilah yang terbuat dari bahan kayu. Generator DC magnet permanen digunakan untuk generator di sumbu horizontal dan posisi turbin angin sumbu vertikal dengan daya maksimum yang dapat dihasilkan pada 800 Watt. Output turbin angin sangat tergantung pada kecepatan angin dan desain turbin. 


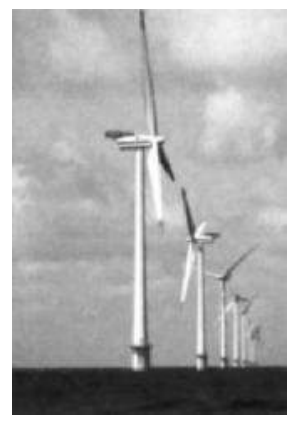

Gambar 1 Turbin angin sumbu horizontal[2]

Maka dalam paper ini dilakukan pengukuran kecepatan angina dan tegangan yang dihasilkan menggunakan variasi desain turbin angina horizontal dan vertical.

\section{TINJAUAN PUSTAKA}

\subsection{Energi Angin}

Energi angin dapat dimanfaatkan sebagai penggerak turbin pada pembangkit listrik tenaga angin. Pemanfaatan energy angina dapat mengurangi ketergantungan terhadap energi fosil dan juga mengurangi efek pada lingkungan.

\subsection{Pembangkit Listrik Tenaga Angin}

\subsubsection{Turbin Angin}

Turbin angin merupakan komponen atau bagian dari kincir angin yang digunakan untuk membangkitkan tenaga listrik. Turbin angin dapat ditemukan pada proses penggilingan padi, pengaliran air irigasi, dan lainnya.

Pembangkit listrik tenaga angin bekerja dengan carai meubah energi angin menjadi energi listrik dengan menggunakan turbin angin atau kincir angin. Energi angin akan memutar turbin angin yang diteruskan memutar rotor pada generator. Generator yang berputar akan menghasilkan energi listrik yang disimpan dalam batere (accu).

Turbin angina memiliki beberapa komponen yaitu blade, poros, generator, ekor pengatur gerak turbin dan lainnya. Gerak turbin angin dibagi dua yaitu gerak sumbu horizontal dan vertical.

\subsubsection{Turbin Angin Sumbu Horizontal}

Turbin angin sumbu horizontal memiliki poros rotor utama dan generator listrik yang diarahkan oleh baling-baling angin. Turbin angin berukuran besar menggunakan sebuah sensor angin yang digerakan oleh servo motor. Dimana terdapat gearbox yang mengubah perputaran kincir yang pelan menjadi lebih cepat berputar. Gambar 1 menunjukan bentuk turbin angina sumbu horizontal.

Blade turbin dibuat kaku agar tidak mengalami daya dorong yang dapat merusak landasan atau dudukan generator pada saat ditimpa oleh angin berkecepatan tinggi.

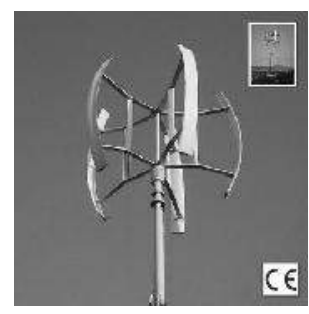

Gambar 2 Turbin angin sumbu vertikal [9]

\subsubsection{Turbin Angin Sumbu Vertikal}

Turbin angin sumbu vertikal memiliki poros atau sumbu rotor utama yang disusun tegak lurus. Turbin angin sumbu vertikal mampu mendayagunakan angin dari berbagai arah. Pada turbin angina sumbu vertikal, generator dan gearbox bisa ditempatkan di bawah atau tanah. Gambar 2 menunjukan bentuk turbin angina sumbu vertical.

\subsection{Konversi Energi Angin}

Prinsip utama pembangkit listrik energy angin adalah mengubah energy mekanik menjadi energi listrik. Besarnya energi yang dapat ditransferkan ke rotor tergantung pada massa jenis udara, luas area dan kecepatan angin.

Energi kinetik poros dapat dihitung dengan persamaan 1 [7]:

$$
\mathrm{E}=\frac{1}{2} m v^{2}(\mathrm{Nm})
$$

Dimana:

$m$ : Massa udara yang bergerak $(\mathrm{kg})$

$v$ : Kecepatan angin $(\mathrm{m} / \mathrm{s})$

Aliran volume $\mathrm{V}$ dihitung dengan menggunakan persamaan 2:

$$
V=v A
$$

Dimana:

$V$ : Laju volume $\left(\mathrm{m}^{3} / \mathrm{s}\right)$

$v:$ Kecepatan angin $(\mathrm{m} / \mathrm{s})$

$A$ : Luas penampang sapuan $\left(\mathrm{m}^{2}\right)$

Sedangkan laju aliran massa dengan kecepatan udara $p$ dihitung dengan menggunakan persamaan 3 [7]:

$$
m=p A v
$$

Persamaan (1-3) menunjukkan energi kinetik dan aliran massa yang melewati suatu penampang melintang A sebagai energi $P$ yang ditunjukkan dengan mensubstitusinya menjadi persamaan 4 [7]:

$$
P=\frac{1}{2} \rho A v^{3}
$$

Dimana:

$\mathrm{P}$ : Daya mekanik $(\mathrm{W})$

$v:$ Kecepatan angin $(\mathrm{m} / \mathrm{s})$

$\rho$ : Densitas udara ( $\rho$ rata-rata $: 1,2 \mathrm{~kg} / \mathrm{m}^{3}$ )

Daya yang dimiliki oleh angin untuk memutar sudu dapat diperoleh dari persamaan 5:

$$
P A=\frac{1}{2} \cdot \rho \cdot A \cdot v 3
$$

Dimana:

PA : Daya angin (Watt) 


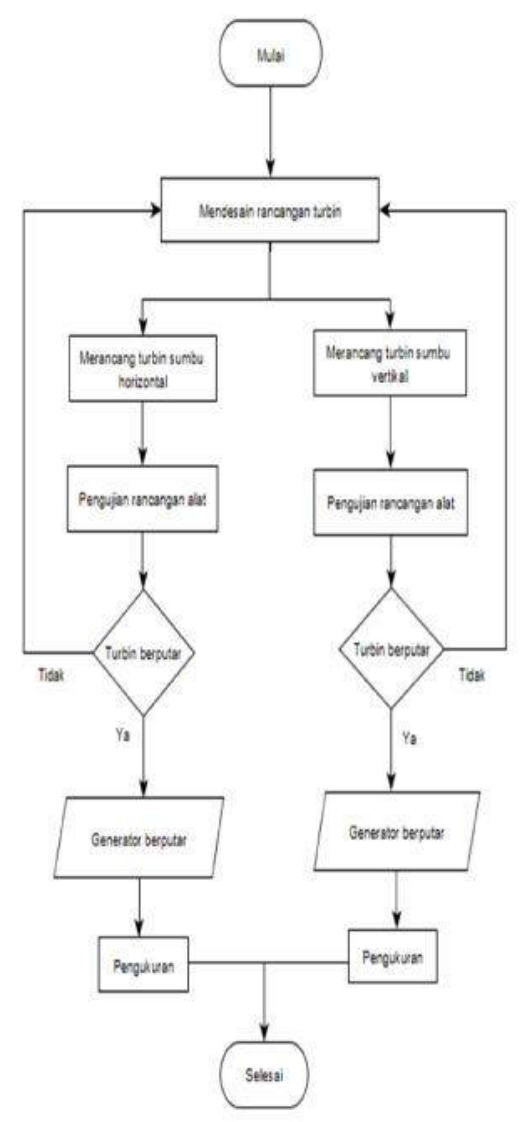

Gambar 3 Langkah perancangan, pembuatan dan kaji eksperimental turbin angin sumbu horizontal dan vertikal

$\rho \quad$ : Masa jenis udara $\left(\mathrm{kg} / \mathrm{m}^{3}\right)$

A : Luas penampang sapuan $\left(\mathrm{m}^{2}\right)$

$\mathrm{v}:$ Kecepatan angin $(\mathrm{m} / \mathrm{s})$

\section{METODE PENELITIAN}

Metode penelitian yang dilakukan adalah metode peracangan, pembuatan dan uji eksperimental turbin angin sumbu horizontal dan vertical yang diawali dari pengamatan kerja turbin angina horizontal dan dilanjutkan dengan turebin angin vertikal. Urutan proses penelitian dapat dilihat pada Gambar 3.

\subsection{Perancangan Pembangkit Listrik Tenaga Angin}

\section{dengan Turbin Sumbu Horizontal}

Desain turbin horizontal dapat dilihat pada Gambar 4. Turbin angin sumbu horizontal memiliki tiga buah bilah yang terhubung pada satu poros yang terkopel dengan generator yang akan menghasilkan energi listrik ketika berputar.

Blade turbin angin sumbu horizontal ini dibuat dari bahan kayu dengan berat yang sama. Bentuk blade turbin angin sumbu horizontal dapat dilihat pada Gambar 5.

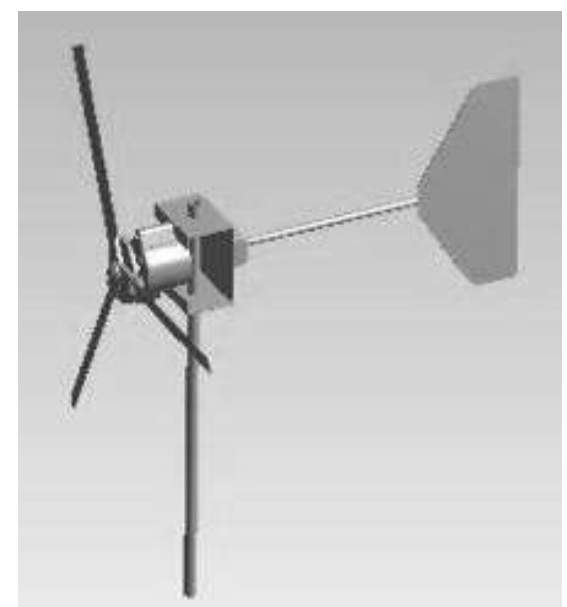

Gambar 4 Desain perancangan turbin angin sumbu horizontal

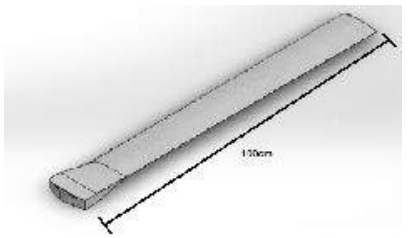

Gambar 5 Blade turbin angin sumbu horizontal

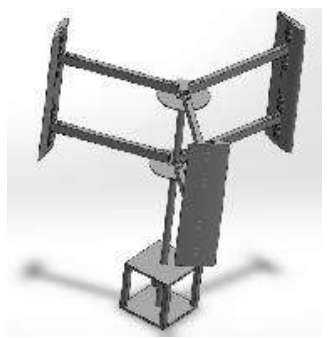

Gambar 6 Desain perancangan turbin angin sumbu vertikal

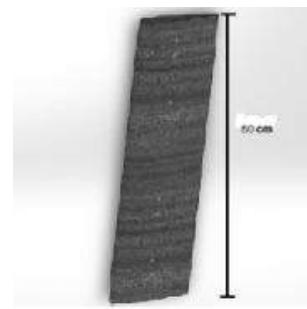

Gambar 7 Bilah turbin angin sumbu vertikal

\subsection{Perancangan Pembangkit Listrik Tenaga Angin dengan Turbin Sumbu Vertikal}

Desain turbin angin sumbu vertikal dapat dilihat pada Gambar 6.

Turbin angin sumbu vertikal yang dirancang adalah jenis Savonius yang memiliki tiga buah bilah yang terhubung pada satu poros. Poros turbin terkopel dengan generator yang akan menghasilkan energi listrik ketika berputar. Blade turbin angin sumbu vertikal dibuat dari 


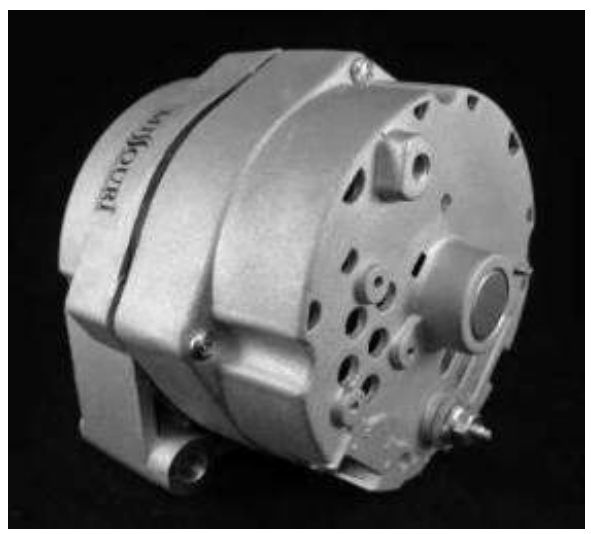

Gambar 8 Generator DC magnet permanen

bahan kayu dengan berat yang sama dimana bentuk blade turbin angin sumbu vertikal dapat dilihat pada Gambar 7.

\subsection{Generator DC}

Generator magnet permanen dengan kapasitas maksimal 800 Watt digunakan dalam kajian ini. Generator terkopel dengan turbin angin pada posisi turbin horizontal maupun vertika seperti terlihat pada Gambar 8

Generator yang digunakan pada penelitian ini adalah generator jenis magnet permanen dengan rotor bermagnet Neodimium. Rotor generator memiliki 7 buah magnet. Generator ini dapat berputar dua arah untuk menghasilkan daya listrik. Pada putaran 150 RPM generator dapat menghasilkan tegangan sebesar 12 Volt. Generator ini bagus untuk pengisian baterai 24 volt dan 12 volt dan ideal untuk kecepatan awal angin rendah.

\subsection{Alat Ukur}

Alat ukur yang digunakan adalah anemometer, multimeter, tachometer, mistar dan lainnya. Parameterparameter keluaran generator yang diukur adalah tegangan, arus dan daya. Tegangan dan arus keluaran generator diukur menggunakan multimeter, sedangkan daya keluaran generator diukur menggunakan wattmeter.

\section{HASIL DAN PEMBAHASAN}

\subsection{Pengujian Pembangkit Listrik Tenaga Angin Sumbu Horizontal}

Pengujian ini dilakukan dengan mengukur kecepatan angin dan putar turbin sumbu horizontal. Kecepatan angin diukur menggunakan anemometer, sedangkan kecepatan putar turbin diukur menggunakan tachometer. Bentuk turbin angina horizontal yang dihasilkan dapat dilihat pada Gambar 10.

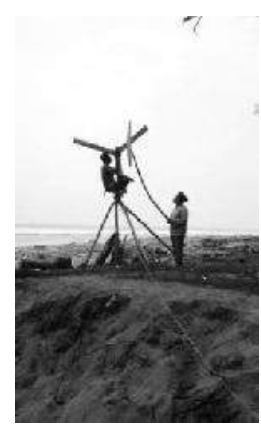

Gambar 10 Pembangkit listrik tenaga angin sumbu horizontal

Tabel 1 Hasil Pengujian Pembangkit Listrik Tenaga Angin Sumbu Horizontal

\begin{tabular}{|c|c|c|c|c|}
\hline $\begin{array}{l}\text { Kec. } \\
\text { Angin }\end{array}$ & $\begin{array}{c}\text { Kondisi } \\
\text { Turbin/ } \\
\text { Generator }\end{array}$ & $\begin{array}{c}\text { Kec. } \\
\text { Turbin } \\
\text { (RPM) }\end{array}$ & $\begin{array}{l}\text { Teg. } \\
\text { (V) }\end{array}$ & $\begin{array}{l}\text { Arus } \\
\text { (A) }\end{array}$ \\
\hline 0.5 & $\begin{array}{c}\text { Belum } \\
\text { Berputar }\end{array}$ & - & - & - \\
\hline 1 & $\begin{array}{c}\text { Belum } \\
\text { Berputar }\end{array}$ & - & - & - \\
\hline 1.5 & $\begin{array}{l}\text { Belum } \\
\text { Berputar }\end{array}$ & - & - & - \\
\hline 2 & $\begin{array}{c}\text { Belum } \\
\text { Berputar }\end{array}$ & - & - & - \\
\hline 2.5 & $\begin{array}{c}\text { Belum } \\
\text { Berputar }\end{array}$ & - & - & - \\
\hline 3 & $\begin{array}{c}\text { Belum } \\
\text { Berputar }\end{array}$ & - & - & - \\
\hline 3.5 & Berputar & 150 & 12 & 1.46 \\
\hline 4 & Berputar & 172 & 16 & 2.4 \\
\hline 4.5 & Berputar & 184 & 17.4 & 2.52 \\
\hline 5 & Berputar & 195 & 18.5 & 2.59 \\
\hline 5.5 & Berputar & 210 & 20 & 2.63 \\
\hline 6 & Berputar & 228 & 21 & 2.7 \\
\hline 6.5 & Berputar & 236 & 21.7 & 2.73 \\
\hline 7 & Berputar & 243 & 21.9 & 2.79 \\
\hline 7.5 & Berputar & 250 & 22 & 2.8 \\
\hline 8 & Berputar & 258 & 22.9 & 3.45 \\
\hline 8.5 & Berputar & 265 & 23.4 & 3.5 \\
\hline 9 & Berputar & 281 & 23.8 & 3.6 \\
\hline 9.5 & Berputar & 294 & 24.3 & 3.7 \\
\hline
\end{tabular}

Pada pengujian ini pembangkit listrik tenaga angina sumbu horizontal diletakkan di pinggiran pantai dengan tinggi tiang 2 meter. Hasil pengujian dapat dilihat pada Tabel 1 dan Gambar 11-12. Dari Tabel 1 terlihat bahwa turbin angina sumbu horizontal berputar pada kecepatan angina $3,5 \mathrm{~m} / \mathrm{s}$ dengan kecepatan turbin 150 rpm dengan tegangan $12 \mathrm{~V}$ dan arus 1,46 A. Peningkatan kecepatan angina juga akan meningkatkan putaran dan tegangan keluaran generator seperti terlihat 


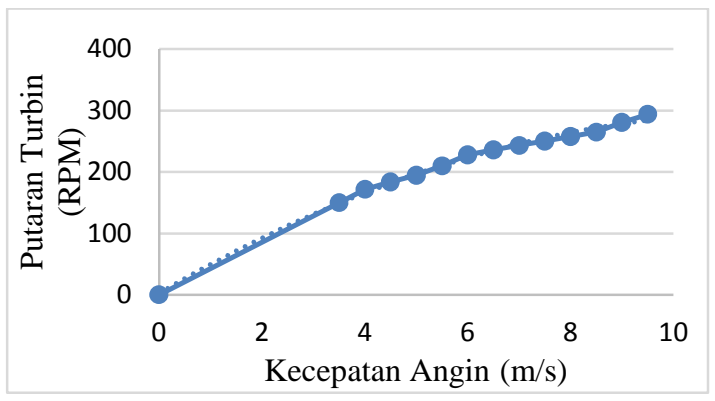

Gambar 11 Kecepatan angin terhadap putaran turbin

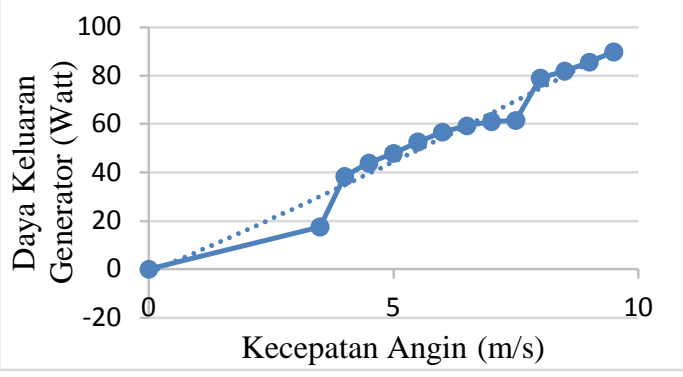

Gambar 12 Kecepatan angin terhadap daya keluaran generator

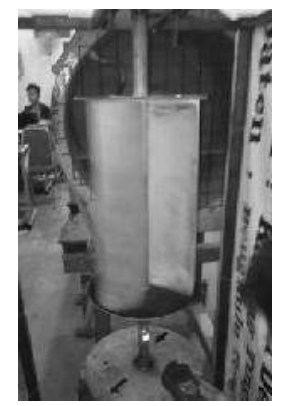

Gambar 13 Pengujian pembangkit listrik tenaga angin sumbu vertical

pada Tabel 1 yaitu saat kecepatan angina mencapai $9 \mathrm{~m} / \mathrm{s}$ kecepatan turbinnya adalah $294 \mathrm{rpm}$ dengan keluaran tegangan $24,3 \mathrm{~V}$ dan $3.7 \mathrm{~A}$.

Gambar 11 dan 12 menunjukan semakin besar kecepatan angin maka putaran turbin semakin besar dan daya luaran generator juga semakin tinggi.

\subsection{Pengujian Pembangkit Listrik Tenaga Angin Sumbu Vertikal}

Pengujian ini dilakukan dengan mengukur kecepatan angin dan putar turbin sumbu vertikal. Bentuk turbin angina vertikal yang dihasilkan dapat dilihat pada Gambar 13.

Hasil pengujian dapat dilihat pada Tabel 2 dan Gambar 14-15. Dari Tabel 2 terlihat bahwa turbin angina sumbu vertikal berputar pada kecepatan angina yang lebih tinggi dibanding dengan turbin angin sumbu
Tabel 2 Hasil Pengujian Pembangkit Listrik Tenaga Angin

\begin{tabular}{|c|c|c|c|c|}
\hline \multicolumn{5}{|c|}{ Sumbu Vertikal } \\
\hline $\begin{array}{l}\text { Kec. } \\
\text { Angin }\end{array}$ & $\begin{array}{c}\text { Kondisi } \\
\text { Turbin/ } \\
\text { Generator }\end{array}$ & $\begin{array}{c}\text { Kec. } \\
\text { Turbin } \\
\text { (RPM) }\end{array}$ & $\begin{array}{l}\text { Teg } \\
(\mathrm{V})\end{array}$ & $\begin{array}{c}\text { Arus } \\
\text { (A) }\end{array}$ \\
\hline 0.5 & $\begin{array}{c}\text { Belum } \\
\text { Berputar }\end{array}$ & - & - & - \\
\hline 1 & $\begin{array}{l}\text { Belum } \\
\text { Berputar }\end{array}$ & - & - & - \\
\hline 1.5 & $\begin{array}{l}\text { Belum } \\
\text { Berputar }\end{array}$ & - & - & - \\
\hline 2 & $\begin{array}{c}\text { Belum } \\
\text { Berputar }\end{array}$ & - & - & - \\
\hline 2.5 & $\begin{array}{c}\text { Belum } \\
\text { Berputar }\end{array}$ & - & - & - \\
\hline 3 & $\begin{array}{l}\text { Belum } \\
\text { Berputar }\end{array}$ & - & - & - \\
\hline 3.5 & $\begin{array}{c}\text { Belum } \\
\text { Berputar }\end{array}$ & - & - & - \\
\hline 4 & $\begin{array}{l}\text { Belum } \\
\text { Berputar }\end{array}$ & - & - & - \\
\hline 4.5 & $\begin{array}{l}\text { Belum } \\
\text { Berputar }\end{array}$ & - & - & - \\
\hline 5 & $\begin{array}{l}\text { Belum } \\
\text { Berputar }\end{array}$ & - & - & - \\
\hline 5.5 & $\begin{array}{c}\text { Belum } \\
\text { Berputar }\end{array}$ & - & - & - \\
\hline 6 & $\begin{array}{c}\text { Belum } \\
\text { Berputar }\end{array}$ & - & - & - \\
\hline 6.5 & Berputar & 133 & 9 & 1.15 \\
\hline 7 & Berputar & 144 & 11.8 & 1.41 \\
\hline 7.5 & Berputar & 154 & 13.5 & 1.82 \\
\hline 8 & Berputar & 176 & 15.2 & 2.26 \\
\hline 8.5 & Berputar & 182 & 16.84 & 2.33 \\
\hline 9 & Berputar & 190 & 18.3 & 2.54 \\
\hline 9.5 & Berputar & 209 & 19.52 & 2.67 \\
\hline 10 & Berputar & 254 & 22.3 & 3.2 \\
\hline
\end{tabular}

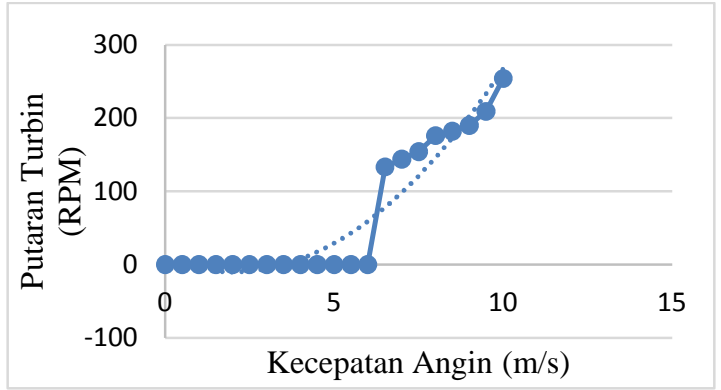

Gambar 14 Kecepatan angin terhadap putaran turbin

horizontal yaitu $6,5 \mathrm{~m} / \mathrm{s}$ dengan kecepatan turbin 133 rpm dengan tegangan $9 \mathrm{~V}$ dan arus 1,15 A. Peningkatan kecepatan angina juga akan meningkatkan putaran dan tegangan keluaran generator seperti terlihat pada Tabel 1 


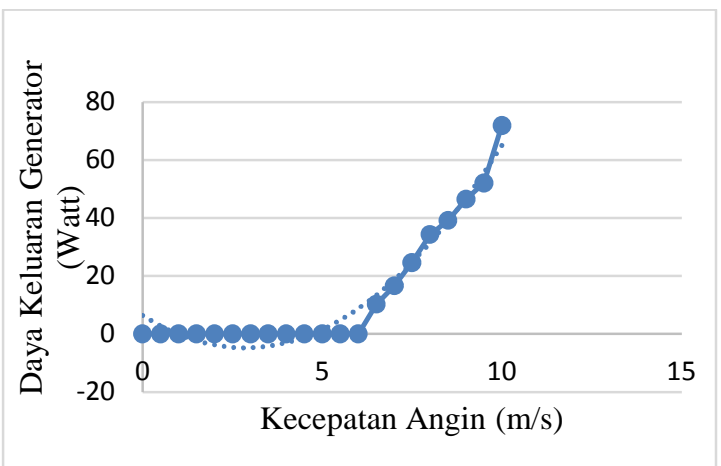

Gambar 15 Grafik hubungan antara kecepatan angin terhadap daya keluaran generator

yaitu saat kecepatan angina mencapai $9 \mathrm{~m} / \mathrm{s}$ kecepatan turbinnya adalah $190 \mathrm{rpm}$ dengan keluaran tegangan $18,3 \mathrm{~V}$ dan $2.54 \mathrm{~A}$.

Gambar 14 dan 15 menunjukan fenomena yang sama dengan hasil pengujian turbin sumbu horizontal dimana semakin besar kecepatan angin maka putaran turbin semakin besar dan daya luaran generator juga semakin tinggi.

\section{PENUTUP}

\subsection{Kesimpulan}

Dari hasil rancangan, pembuatan dan pengujian turbin angina arah sumbu horizontal dan vertical didapatkan kesimpulan yaitu:

1. Turbin angin dengan sumbu horizontal menghasilkan putaran dan tegangan turbin terendah pada kecepatan angina $3,5 \mathrm{~m} / \mathrm{s}$ dan turbin angina sumbu vertical pada kecepatan angina $6,5 \mathrm{~m} / \mathrm{s}$.

2. Kecepatan putar turbin dan tegangan terendah untuk sumbu horizontal adalah dengan kecepatan angina $3,5 \mathrm{~m} / \mathrm{s}$ dengan kecepatan turbin $150 \mathrm{rpm}$ dengan tegangan $12 \mathrm{~V}$ dan arus 1,46 $\mathrm{A}$ dan kecepatan angin maksimal $9 \mathrm{~m} / \mathrm{s}$ kecepatan turbinnya adalah $294 \mathrm{rpm}$ dengan keluaran tegangan 24,3 V dan 3.7 A.

3. Kecepatan putar turbin dan tegangan terendah untuk sumbu horizontal adalah dengan kecepatan angina $6,5 \mathrm{~m} / \mathrm{s}$ dengan kecepatan turbin $133 \mathrm{rpm}$ dengan tegangan $9 \mathrm{~V}$ dan arus 1,15 A dan kecepatan angin maksimal $9 \mathrm{~m} / \mathrm{s}$ kecepatan turbinnya adalah $190 \mathrm{rpm}$ dengan keluaran tegangan 18,3 V dan 2.54 A.

4. Performance turbin angin dipengaruhi oleh posisi sumbu gerak turbin dan angina, dimana semakin besar putaran angina maka kecepatan putar turbin dan tegangan serta arus yang dihasilkan akan semakin besar.

\section{DAFTAR PUSTAKA}

[1] Indriani, A., Hendra, Perancangan Pembangkit Listrik Gelombang Laut Menggunakan
Sistem Pneumatik Selinder Tabung, PROSIDING SEMINAR NASIONAL AVoER IV Tahun 2012 Universitas Sriwijaya Fakultas Teknik

[2] Indriani, A., Sitepu, D., Hendra, Unjuk Kerja Generator Sinkron dengan Sistem Translasi Menggunakan Variasi Bentuk Magnet NdFeB Pembangit Listrik Tenaga Gelombang Laut, Prosiding Seminar Nasional Teknik Elektro (FORTEI 2017) ISBN 978-602-6204-24-0 Fakultas Teknik Universitas Negeri Gorontalo, 18 Oktober 2017.

[3] Ramadhan, A.I., Diniardi, E., Mukti, S.H., Analisis Desain Sistem Pembangkit Listrik Tenaga Surya Kapasitas 50 WP, Teknik, 37(2), 2016, 59-63

[4] Suriadi, Syukri, M., Perencanaan Pembangkit Listrik Tenaga Surya (PLTS) Terpadu Menggunakan Software PVSYST Pada Komplek Perumahan Di Banda Aceh, Jurnal Rekayasa Elektrika, Vol 9, No 2 (2010)

[5] Adriani, Perancangan Pembangkit Listrik Kincir Angin Menggunakan Generator Dinamo Drillini Terhadap Empat Sumbu Horizontal, Jurnal Instek, Vol. 3 No. 1, April 2018

[6] Hidayatullah, N., Ningrum, N.H.K., Optimalisasi Daya Pembangkit Listrik Tenaga Angin Turbin Sumbu Horizontal Dengan Menggunakan Metode Maximum Power Point Tracker, Journal Of Electrical Electronic Control And Automotive Engineering (Jeecae), Vol.1, No.1, Oktober 2016

[7] Basri, M.H., Djaman, Rancang Bangun Dan Desain Prototype Pembangkit Listrik Tenaga Bayu Model Savonious, Jurnal Simet Vol 9, No 2 (2019)

[8] Towler F. 2014. Chapter 9 - Wind Energy, The Future Of Energy, Hal 187-214.

[9] Permana Edo. 2012. "Rancang Bangun Pembangkit Listrik Tenaga Angin". Politeknik Negeri Sriwijaya. Palembang.

[10] Asran, Ezwarsyah. 2009. "Prototipe Turbin Angin Skala Kecil Tipe Vertikal Axis untuk Battery Charging di Daerah Remote Area". UNIMAL. Aceh. 